\title{
COOPERAÇÃO INTERLOCAL EM TRÊS VERSÕES: PARCERIAS, GOVERNANÇA REGIONAL E METROPOLITANA
}

\section{INTERLOCAL COOPERATION IN THREE VERSIONS: PARTNERSHIPS, REGIONAL GOVERNANCE AND METROPOLITAN REGIONS}

José Angelo Machado ${ }^{1}$

\section{RESUMO}

Neste trabalho buscamos responder a como a literatura internacional sobre cooperação entre governos locais se distingue internamente quanto à natureza das organizações que lhe dão suporte e como estas articulam os interesses de seus associados. Mobilizando como metodologia a revisão bibliográfica com foco em problemas de cooperação interlocal, até que fosse alcançado ponto de saturação, assumimos como objetivo identificar diferentes agrupamentos de estudos tomando por critério tipologia de riscos de colaboração proposta no âmbito da Teoria da Ação Coletiva Institucional. Ao final identificamos três agrupamentos: parcerias voluntárias, como associações para realização de interesses comuns, governança regional e gestão de regiões metropolitanas, estas últimas incorporando também temas para os quais governos locais atribuem diferente saliência ou mesmo se colocam em posição conflitante, embora sob condições distintas. Os agrupamentos identificados se referem a obstáculos e dilemas institucionais próprios para a cooperação, tanto do ponto de vista dos poderes institucionais delegados à associação quanto da amplitude do escopo da sua agenda.

Palavras-chave: Cooperação interlocal, custos de transação, parcerias intermunicipais, governança regional, regiões metropolitanas.

\section{ABSTRACT}

In this paper, we intend to respond to how the international literature on cooperation between local governments differs internally regarding the nature of the organizations that support it and how these

\footnotetext{
1 José Angelo Machado é graduado em Psicologia, mestre em Psicologia, doutor em Ciências Humanas / Sociologia e Política pela UFMG e Visiting Scholar na Universidade da Pennsylvania. Professor associado do DCP, exerceu a chefia de departamento entre 2013 e 2015 e foi vice-coordenador do PPGCP entre 2019 e 2020. Pesquisas e publicações cobrem temas relativos ao federalismo; relações intergovernamentais; interação estratégica e problemas de cooperação; gestão e políticas públicas. Afiliação:Universidade Federal de Minas Gerais Lattes:http://lattes.cnpq.br/9345341099863361. ORCID:https://orcid.org/0000-0002-8023-9526. E-mail:joseangelo @fafich.ufmg.br
} 
articulate the interests of their members. Mobilizing as a methodology the literature review focusing on interlocal cooperation problems, until reaching the saturation point, we assumed the objective of identifying different groups of studies taking as a criterion the typology of collaboration risks proposed in the scope of the Institutional Collective Action Theory. At the end, we identified three groups: voluntary partnerships, such as associations for the realization of common interests, regional governance and management of metropolitan regions, the latter also incorporating themes to which local governments attribute different emphasis or even put themselves in a conflicting position, albeit under different conditions. The identified groupings refer to institutional obstacles and dilemmas for cooperation, both from the point of view of the institutional powers delegated to the association and the breadth of the scope of its agenda.

Keywords: Interlocal cooperation, transaction costs, intercity partnerships, regional governance, metropolitan regions.

\section{INTRODUÇÃO}

Neste trabalho identificamos três agrupamentos de estudos dedicados a problemas de cooperação entre governos locais no âmbito da literatura internacional: parcerias voluntárias, governança regional e gestão de regiões metropolitanas. Argumentamos que tais agrupamentos não apenas se referem a tipos distintos de associações como também, em cada um, lidam com diferentes formas de articulação entre os interesses dos associados. Parcerias voluntárias são associações intermunicipais para gestão de interesses comuns, constituindo-se em torno de organizações baseadas no consenso entre as partes; associações de governança regional ou gestão metropolitana lidam também, embora sob condições distintas, com interesses não comuns e incluem temas para os quais governos locais atribuem diferente saliência ou mesmo se colocam em posição conflitante. Ao articular distintamente os interesses de seus membros, tais associações lidam com obstáculos e dilemas institucionais próprios para o desenvolvimento da ação cooperativa, tanto do ponto de vista dos poderes atribuídos a elas quanto da amplitude do escopo da agenda cooperativa.

Tomando como ponto de partida o federalismo brasileiro pós Constituição Federal de 1988, combinou-se descentralização política, administrativa e fiscal à redefinição do status constitucional dos governos locais, então alçados à condição de terceiro ente federado. A essas mudanças se sucedeu um surto de criação de municípios que, até meados dos 90, acresceu mais 1.385 novos entes locais (TOMIO, 
2005) e acirrou ainda mais a fragmentação político-territorial. Ao mesmo tempo a Constituição de 1988 estabeleceu novas garantias sociais de caráter nacional cuja materialização exigiria um esforço de integração vertical e horizontal entre as ações de entes vinculados aos três níveis de governo, tornando a cooperação intergovernamental condição necessária para construção das políticas públicas correspondentes.

A articulação vertical entre diferentes níveis de governo foi relativamente bem-sucedida, valendo-se de instrumentos de coordenação federativa como constrangimentos legais e mecanismos de indução financeira setorialmente construídos a partir do Executivo Federal (ABRUCIO, 2005; ALMEIDA, 2005 E 2007; ARRETCHE, 2012), em que pese assimetrias entre capacidades locais tenham levado a resultados muitas vezes heterogêneos do ponto de vista territorial (PIRES \& GOMIDE, 2016; LAVALLE ET AL., 2020). Mas em sentido horizontal, que articula entes federados de mesmo nível, a avaliação sobre o sucesso das novas formas institucionais construídas é menos conclusiva e inclui percepções mais ou menos otimistas sobre seu potencial de generalização em experiências como os consórcios intermunicipais (ROCHA \& FARIA, 2004; LINHARES ET ALI, 2012; MACHADO, 2010 E 2014) ou a gestão das regiões metropolitanas (FERNANDES, 2012; LIPPI, 2012; GOUVÊA, 2001; GARSON, 2009; LACERDA, 2011). Mais que isso, chama atenção que a literatura brasileira apresente, em geral, um caráter predominantemente descritivo e com baixo diálogo entre os diferentes estudos quanto às implicações teóricas dos seus achados, especialmente em se tratando daqueles voltados para diferentes tipos de associações.

Na literatura internacional, o balanço das experiências de cooperação horizontal entre governos locais também abriga entusiasmo e frustração. Em países da Organização para a Cooperação e Desenvolvimento Econômico (OCDE) há parcerias voluntárias de sucesso (LOFLER, 2000), mas há dúvidas ou ponderações aos seus ganhos em termos de eficiência (NIAOUNAKIS \& BLANK, 2017; ALLERS \& DE GREEF, 2018), assim como também têm sido apontadas limitações de integração ou superação das desigualdades internas em regiões metropolitanas (FURMANKIEWICZ, 2011; SAVITCH \& ADHIKARI, 2016). Nos Estados Unidos, o sucesso das organizações regionais geridas por governos locais varia substancialmente a depender de uma série de condições, o que tem aumentado o interesse pela identificação dos fatores facilitadores ou obstáculos (FEIOCK, 2005 E 2007; GERBER \& GIBSON, 2005 \& 2009). Na China a cooperação entre governos locais é um condicionante importante no cumprimento das metas de crescimento das economias regionais (CHEN ET ALI, 2017), nem sempre com sucesso. 
Entretanto, a despeito de compartilhar da mesma bipolaridade quanto a uma avaliação otimista ou pessimista das experiências de cooperação horizontal, como de resto ocorre na literatura brasileira, nos indagamos neste trabalho quanto a que forma seria possível distinguir os agrupamentos de estudos realizados no âmbito da literatura internacional sobre o tema quanto à natureza das organizações tomadas como objeto? E, dando um passo a mais, como as organizações tomadas por objeto nos diferentes agrupamentos articulariam os interesses dos seus associados? Neste artigo, sob o enquadramento teórico da Teoria da Ação Coletiva Institucional e tomando por referência tipologia sobre riscos de colaboração proposto por Feiock (2013), respondemos a essas questões a partir de revisão da literatura internacional em torno dos problemas de cooperação entre governos locais ${ }^{2}$, buscando assegurar diversidade geográfica para os trabalhos analisados.

A Teoria da Ação Coletiva Institucional tem se beneficiado de avanços recentes no campo da Teoria do Jogos, como aquele empreendido por Holzinger (2003). Em um trabalho de revisão conceitual e dos modelos formais envolvidos em problemas de ação coletiva, esta autora identificou diferentes estruturas de interação que obstaculizam a cooperação para além do clássico problema de deserção originalmente tratado por Olson (1968), e que tem no Dilema do Prisioneiro ${ }^{3}$ sua representação. Foram também aí incluídos os problemas distributivos (múltiplos equilíbrios com ganhos assimétricos para dois jogadores, representado pelo Battle of $\operatorname{Sexes}^{4}$ ) e os problemas de coordenação (em que a transição de um equilíbrio subótimo para um ótimo supõe uma mudança coordenada de estratégia pelos dois

\footnotetext{
${ }^{2}$ A revisão bibliográfica empreendida não seguiu técnicas de revisão sistemática, dando-se em torno das variações, em inglês, para a expressão problemas de cooperação entre governos locais ou governos municipais. Foram privilegiados estudos de caráter analítico, embora estudos descritivos abrangendo vários casos ou teóricos não tenham sido descartados. A revisão identificou autores e trabalhos citados com maior frequência e foi estendida até que se atingisse um nível de saturação considerado satisfatório.

${ }^{3}$ Criado como recurso didático pelo matemático Alfred Tucker nos anos 40 , refere-se ao contexto estratégico em que dois suspeitos são capturados próximos ao local de um suposto crime, sendo interrogados em separado pelo investigador. Sob as condições fixadas por este, a não cooperação com o parceiro de delito (ou deserção) é a estratégia com maior recompensa para cada suspeito, às custas de enorme prejuízo para o mesmo, superando até mesmo mesmo aquela obtida sob a cooperação de ambos. O grande interesse por este jogo está no fato de que, não importa qual seja a escolha do outro, para cada um o melhor resultado advém da deserção, que daí se torna a estratégia dominante, resultando para ambos em um equilíbrio sub ótimo.

${ }^{4}$ Criado nos anos 50, representa um contexto interativo em que há mais de um equilíbrio possível, porém com recompensas assimetricamente opostas entre os jogadores. Originalmente se refere ao contexto interativo em que um casal quer se encontrar, mas sem que tenham chegado previamente a um acordo sobre onde fazê-lo. Com base no estereótipo cultural, o homem prefere que seja numa luta e a mulher em uma apresentação de balé. Se ambos têm em comum o interesse de estar juntos antes que sós, também têm interesses conflitantes sobre onde estarem juntos, do que decorrem dois equilíbrios possíveis sobre os quais os jogadores têm preferências opostas.
} 
jogadores, representado pelo Stag $\left.H u n t^{5}\right)$. Neste último caso haveria interesse comum das partes, mas o sucesso da opção pela cooperação por um dependeria de que o outro também adotasse a mesma estratégia. Para problemas distributivos, haveria interesses conflitantes ao lado dos comuns, de modo que partes teriam preferências distintas sobre os desfechos possíveis, dificultando a concordância em torno da pauta cooperativa comum.

Em direção similar, Feiock (2013) propôs uma tipologia tripartite para os riscos de colaboração entre entes governamentais: o risco de deserção, de coordenação e de divisão. O primeiro corresponde aos casos em que as partes são tentadas a tomar decisões unilaterais que poderiam resultar em uma condição pior para a outra parte; o segundo, àqueles em que obstáculos impedem que atuem juntos ou adotem um padrão comum nos casos em que a interconexão de estratégias é crítica para o sucesso; o último, àqueles em que os envolvidos têm dificuldades para chegar a um acordo quanto às alternativas de cooperação, uma vez que Ihes oferecem distribuição oposta de ganhos. Dessa tripartição, optamos por extrair como critério chave a ser observado nos estudos um de seus aspectos mais básicos: 0 envolvimento exclusivo ou não dos interesses comuns dos governos locais.

Este artigo está organizado em quatro seções, afora esta introdução e a conclusão. Na próxima, tratamos dos estudos sobre parcerias voluntárias entre governos locais, em geral interessados na aferição dos ganhos em economias de escala ou eficiência. Na segunda seção, apresentamos os estudos de governança regional, originários do ambiente acadêmico norte americano e interessados nos fatores explicativos para variações encontradas nas organizações voluntárias em se atribui algum nível de autoridade para ação regional própria. Na terceira, tratamos dos estudos sobre gestão das regiões metropolitanas que, embora apresentem zonas de interseção com as literaturas anteriores, incidem mais diretamente no debate sobre as limitações para realizar objetivos regionais coletivamente. $\mathrm{Na}$ quarta e última seção, discutimos as implicações dos resultados encontrados para responder às questões de origem deste trabalho.

\footnotetext{
${ }^{5}$ Baseado em descrição de Rousseau, trata de contexto interativo em que dois caçadores devem optar por caçar, individualmente, lebres ou, conjuntamente, um veado. Neste último caso a recompensa para cada um é maior mas requer de ambos a cooperação recíproca, havendo riscos de que o outro caçador tenha desistido e caçado lebres enquanto um deles permanecia escondido à espera do veado. Diferente do Dilema do Prisioneiro, as recompensas da cooperação recíproca são superiores à deserção, quando o outro jogador coopera, configurando um dos resultados em equilíbrio. A confiança no outro é tensionada pelos riscos de que qualquer um dos dois jogadores reavalie sua promessa durante o jogo.
} 


\section{PARCERIAS VOLUNTÁRIAS}

Estudos sobre parcerias voluntárias entre governos locais são bastante diversificados quanto às organizações abrangidas ainda que, na sua grande maioria, o foco recaia sobre o debate em torno dos ganhos de eficiência para produção ou provisão compartilhada de bens públicos, em detrimento de trabalhos que enfatizam as motivações dos gestores locais para adesão ou não à cooperação. Nestes estudos o foco econométrico suplanta o foco nas relações intergovernamentais.

As parcerias intergovernamentais se caracterizam por reunir dois ou mais entes de governo para formular e implementar conjuntamente determinados programas e ações (LOFLER, 2000) e podem se deter em três finalidades principais. A primeira, produção conjunta de bens ou serviços que, agregando ganhos de economia de escala e gerando valores quantificáveis, favorece acordos quanto à divisão dos custos e benefícios entre associados, embora sob poucos incentivos para o controle do seu desempenho global. A segunda finalidade seria a gestão de recursos comuns buscando a sustentabilidade do seu uso de modo a afastar a exploração predatória, mas geralmente teriam foco na aplicação de procedimentos e normas. Por fim, a terceira seria promover investimentos conjuntos de modo a distribuir custos de externalidades positivas entre governos locais para empreendimentos que beneficiariam a região como um todo (LOFLER, 2000).

Tipicamente, trabalhos sobre parcerias voluntárias se voltam para associações que buscam a primeira finalidade, focando ganhos de eficiência ou realização de economias de escala sob o compartilhamento na produção de serviços ou bens públicos. Trata-se de literatura predominantemente europeia, em grande medida interessada em comparar resultados da cooperação intermunicipal com aqueles obtidos sob outras alternativas destinadas a contornar efeitos da fragmentação territorial, como a amalgamação ou a privatização (BEL \& WARNER, 2015). Neste debate, a distinção entre eficiência técnica e eficiência alocativa serve de base para críticas às reformas de escala territorial (amalgamação) que, ao privilegiar a primeira - maiores níveis de output sob montantes fixos de recursos ou do mesmo nível de output com menos recursos - negligencia a segunda - maximização do bem-estar social pela adequação da oferta às diferentes demandas por bens públicos. Assim, a anexação de unidades locais para formar jurisdições maiores levaria a ganhos de economias de escala às custas da padronização da oferta de serviços e redução da capacidade de atender preferências espacialmente heterogêneas, gerando perdas de bem-estar social (TAVARES \& FEIOCK, 2013). Parcerias voluntárias, por sua vez, teriam capacidade para promover simultaneamente as duas formas de eficiência: governo local 
proveriam bens e serviços segundo as preferências locais (eficiência alocativa) e a produção conjunta proveria bens de interesse comum em maior escala (eficiência técnica). Já a privatização de serviços associados poderia não levar aos mesmos níveis ganhos de economia de escala e traria consigo maiores riscos de problemas de agência (BEL \& FAGEDA, 2006).

Estudos vinculados a este campo de investigação, entretanto, se diferenciam frequentemente quanto à avaliação de seus resultados, ainda que haja zonas de convergência. Bel \& Fageda (2006) encontraram maior redução de custos nos serviços de coleta de resíduos sólidos e fornecimento de água na Espanha sob a cooperação intermunicipal valendo-se de empresas públicas locais. Andrews \& Entwistle (2010) identificaram ganhos de eficiência, efetividade e redução de desigualdades a partir das parcerias firmadas entre departamentos de serviços de governos locais no País de Gales, ainda que tais ganhos variem por setor governamental. Segundo este último trabalho, associações interlocais com parcerias público-privadas apresentaram resultados inferiores às parcerias públicas em termos de efetividade e equidade. Já Niaounakis \& Blank (2017) e Allers \& Greef (2018) analisaram ganhos de escala das Intermunicipal Organizations destinadas à arrecadação de impostos na Holanda, tendo identificado efeitos positivos ainda que não significantes, como esperado, mas também diferenciados conforme porte populacional dos municípios. Menos otimistas foram as conclusões de Frère, Leprince \& Paty (2013), que analisaram os ganhos da cooperação fiscal por meio das Comunidades Intermunicipais ou Etablissements Publics de Coopération Intercommunale (EPCI), na França, e não encontraram nenhum efeito significativo.

Ainda dentro deste agrupamento de estudos, há trabalhos que comparam resultados das parcerias voluntárias com os obtidos pela a amalgamação, porém pendendo majoritariamente em favor das primeiras. Blom-Hansen et ali (2016) mensuraram os níveis redução de despesa pública a partir da reforma na escala dos municípios ocorrida na Dinamarca, mas não encontraram diferença significativa frente ao nível de despesa prévio à amalgamação. Allers \& Geetsema (2016) também não encontraram ganhos agregados significativos em termos de arrecadação ou redução da despesa pública no caso holandês, ainda que tenham percebido efeitos distintos no caso de municípios de diferente porte.

Reunidos geralmente sob uma abordagem econométrica, estes trabalhos estabelecem um diálogo entre si, consolidando em alguma medida a percepção de que a estrutura de custos da produção conjunta, assim como ganhos de eficiência ou de economia de escala, varia a depender do tipo de bens ou serviços públicos prestados ou mesmo de atributos municipais como o porte populacional ou 
localização (BEL \& WARNER, 2015). Os ganhos advindos de parcerias para produção conjunta não seriam, assim, generalizáveis ou passíveis de serem considerados como resultado líquido e certo.

Embora menos requentes nos estudos sobre parcerias intergovernamentais, há trabalhos focando propriamente motivações ou incentivos dos gestores locais para aderir à ação cooperativa. Di Porto et ali (2016) avaliaram a disposição de adesão dos mandatários locais às Comunidades Intermunicipais ou Etablissements Publics de Coopération Intercommunale (EPCI) para benefícios fiscais na região de Brittany, na França, chegando à conclusão de que a probabilidade de cooperar é afetada significativamente pelo fato dos vizinhos estarem ou não cooperando. A retaliação dos eleitores locais detentores de informação sobre as escolhas dos gestores vizinhos e sobre supostos ganhos - ofereceria um incentivo decisivo para a adesão à ação cooperativa, neste caso. Chen et ali (2017), em um ambiente institucional em que governos locais não são responsivos a eleitores - o sistema político chinês identificaram incentivos à cooperação entre municipalidades vinculadas a nove províncias, nas regiões do chamado Pan-Pearl River Delta (Pan-PRD), a partir da aspiração de ascensão na hierarquia de poder do Partido Comunista Chinês. Dirigentes dos governos subnacionais de mesmo nível na hierarquia partidária concorrem entre si para ascenderem na carreira, não tendo incentivos para cooperarem entre si. Porém dirigentes de governos subnacionais que não ocupam mesmo nível hierárquico no Partido teriam incentivos para cooperar, já que nestes casos a ação coordenada potencializaria a realização de metas econômicas por parte de ambos, sem que um rivalize com o outro na ascensão partidária.

A despeito das variações quanto às formas organizacionais a que se referem os estudos nos diferentes países e aos tipos de benefício - se realizar economias de escala e outras formas de eficiência, como no caso europeu, ou promover o desenvolvimento econômico, como no caso chinês - há que se notar que estudos sobre parcerias voluntárias se apoiam empiricamente sobre associações destinadas à realização dos interesses comuns identificados entre os governos locais. O escopo das ações cooperativas não inclui temas sobre os quais os potenciais parceiros não compartilham o mesmo interesse, seja porque Ihes atribuem diferentes níveis de prioridade (ou saliência), seja porque apresentem preferências conflitantes quanto às soluções ou políticas pertinentes. De outro lado, há poucas referências a dilemas institucionais, especialmente conflitos entre associados relativos à formatação dos processos decisórios, que tipicamente assumem regras consensuais ou supermajoritárias, algo em certa medida previsível dado o caráter voluntário das associações. 


\section{GOVERNANÇA REGIONAL}

A literatura sobre governança regional marca uma diferença entre o debate europeu e o norte americano em torno da cooperação intergovernamental, a despeito de ambos se constituírem a partir da preocupação com perdas de eficiência e bem-estar social decorrentes da fragmentação político territorial e da baixa escala populacional assumida por um grande número de governos locais (TAVARES \& FEIOCK, 2013).

Nos Estados Unidos a contratação ou barganha entre governos locais é relativamente comum e, vias de regra, voluntária, sendo bastante frequentes e diversificadas as entidades supralocais constituídas para este fim. Nos estudos sobre essas entidades, entretanto, o esclarecimento dos aspectos que afetam as chances de adesão à cooperação e do escopo desta última assumem o primeiro plano, abrindo caminho para teorias explicativas para o sucesso, fracasso ou dificuldades no encaminhamento da ação conjunta, espaço fortemente ocupado por abordagens oriundas da Teoria da Ação Coletiva (OLSON JR., 1968) e da derivada Teoria da Ação Coletiva Institucional (KWON 2007; TAVARES \& FEIOCK, 2013 SKUZINSKI, 2015). Em sendo voluntária, a adesão e participação destes governos locais nas entidades supralocais pode ser revista a qualquer tempo, dados os baixos custos de saída vigentes em praticamente todos os arranjos existentes (BEL \& WARNER, 2015).

Nesse contexto o termo governança regional foi cunhado para designar um amplo espectro de arranjos cooperativos: desde realizações compartilhadas em pequena escala e envolvendo alguns poucos governos locais - por exemplo para realização de planejamento conjunto ou prestação de serviços - até conselhos multifinalitários, abrangendo regiões formadas por grande número de municipalidades (GERBER \& GIBSON, 2005). Porém um fato decisivo para distinguir entidades supralocais que interessam a estes agrupamentos de estudos é o fato de incorporarem mais que ganhos em economias de escala entre seus objetivos, incluindo também a regulação de externalidades ou transbordamentos de ações de uma localidade sobre outras da região (FEIOCK, 2007), ou seja, aspectos que consideram a integração regional em sentido mais amplo. Dessa ampliação do escopo cooperativo decorreria uma tensão constitutiva na montagem dessas entidades: de um lado, governos locais se veem compelidos a ceder alguma autoridade para que elas realizem a coordenação regional além do estreito limite dos interesses comuns de todos, mas se cederem autonomia por demais, elas poderiam produzir políticas com resultados diferentes dos seus preferidos; de outro, benefícios locais acessíveis ao ceder 
autonomia de menos à entidade supra local poderiam ser menores que aqueles capturados por meio das políticas regionais.

Os níveis de delegação de autonomia para entidades supralocais de caráter regional irão, na prática, variar bastante, o que as torna objeto de interesse dos estudos de governança regional. A maior parte destes concentra-se nos Regional Councils (RCs), que constituem mais de 530 entidades multifinalitárias regionais criadas por lei estadual e presentes em 48 dos 50 estados norte-americanos (GERBER \& GIBSON, 2005; KWON, 2007). Gerber e Gibson (2009) analisaram as mais de 380 Metropolitan Planning Organizations (MPOs), na sua missão de planejamento e implementação das políticas de transporte nas respectivas jurisdições - para o que, além de governos locais, incluem tambem representantes empresariais, sindicais e do setor educacional, dentre outros - considerando seu poder discricionário para alocar recursos federais em projetos na área, ora beneficiando mais interesses locais, ora mais os regionais (GERBER \& GIBSON, 2009). Além dessas, são também incluídas outras organizações regionais mais restritas a alguns estados, como é o caso dos Joint Municipal Planning Act (JMPAs), instituídos no início dos anos 2000 no estado do Michigan para coordenar o planejamento, zoneamento urbano e infraestruturas que afetam várias municipalidades (SKUZINSKI, 2015).

Chama atenção nessa literatura a centralidade do conceito de custos de transação como categoria chave para construção dos mecanismos causais que vinculam, de um lado, escolhas institucionais ou resultados dos processos de cooperação interlocal e, de outro, os incentivos que levam a determinadas escolhas pelos atores locais envolvidos, assumindo lugar especialmente relevante do ponto de vista explicativo. O conceito remete a The Problem of Social Cost, onde Coase (1960) o define como recursos gastos para identificar interessados em realizar uma transação, negociar com os mesmos e chegar a um acordo, formalizar um contrato e aplicar as medidas necessárias para que ele seja observado. A extensão dessa proposição econômica às barganhas entre governos locais, nesta literatura, significa que quanto mais crescem os custos de transação, menos provável que as associações cedam autonomia às associações regionais ou incorporem ações de benefício regional ou, no limite, menos provável que as associações até mesmo se constituam.

Os custos de transação terminam por incorporar os, já mencionados, riscos de colaboração (FEIOCK 2013) - de deserção, de coordenação e de desacordo - presentes em diversos dos fatores que investigados pelos estudos de governança regional (FEIOCK, 2005). Tais fatores incluem: (1) características dos bens ou serviços compartilhados, como sua mensurabilidade, que pode viabilizar ou 
não a quantificação dos benefícios e permitir, assim, uma distribuição proporcional aos custos assumidos por cada associado (TAVARES \& FEIOCK, 2013; FEIOCK, 2005 E 2007; KWON, 2007); (2) homogeneidade ou heterogeneidade das regiões constituídas pelos governos locais, que podem facilitar ou dificultar a identificação de interesses comuns entre potenciais associados (GERBER \& GIBSON, 2005; FEIOCK, 2005 E 2007; KWON, 2007; TAVARES \& FEIOCK, 2013); (3) formato institucional da organização intermunicipal ou regional, que pode conter regras decisórias que favoreçam a predominância de interesses locais sobre os regionais, como exigência de supermaiorias e interesses locais (GERBER \& GIBSON, 2005 E 2009); que pode incluir um grande número de membros nos órgãos decisórios (GERBER \& GIBSON, 2005); ou, ainda, que pode variar quanto ao tipo de agente que toma decisões - se representantes eleitos ou gestores de carreira - e, daí, quanto aos incentivos específicos que os afetam (GERBER \& GIBSON, 2005 E 2009; KWON, 2007; FEIOCK, 2007); (4) estrutura constitucional e legislação nacional ou estadual, que pode impor elevados riscos ou custos sob a formalização de acordos de cooperação (TAVARES \& FEIOCK, 2013); (5) Indução vertical por parte dos governos federal ou estaduais, que pode financiar parte dos custos ou absorver parte dos riscos de cooperação (GERBER \& GIBSON, 2005; KWON, 2007); (6) constituição de redes informais ou o exercício da função de corretagem pelas organizações regionais, que pode fomentar a confiança e comunicação necessárias à realizar de futuros acordos entre governos locais (HAWKINS, 2010; KWON, 2007); e, por fim, (7) valores ou atitudes, tais como disposições comunitaristas ou egoístas dos gestores (SKUZINSKI, 2015) ou opiniões gerais sobre a cooperação (ADELAJA ET ALI, 2010).

Nesse conjunto de estudos, dois aspectos merecem atenção. Em primeiro lugar, para além do número entre pactuantes como tipicamente considerado pela Teoria da Ação Coletiva Institucional, a heterogeneidade entre jurisdições locais parece afetar diferenciadamente os riscos de desacordo e, daí, os custos de transação (FEIOCK, 2013; TAVARES \& FEIOCK, 2013), contribuindo diferenciadamente para produção do desalinhamento entre interesses locais e regionais e dificultando a convergência em torno de prioridades (GERBER \& GIBSON, 2005 E 2009). Ela pode amplificar os efeitos de outros fatores também aqui investigados. Governos locais muito heterogêneos teriam maior trabalho para distribuir custos e benefícios entre si, especialmente quando bens ou serviços provisionados carecem de mensurabilidade ou quando o fazem sob regras decisórias supermajoritárias (FEIOCK, 2005; HAWKINS, 2010). Além disso, na barganha entre governos heterogêneos são menores as chances de que organizações regionais pratiquem políticas redistributivas (GERBER \& GIBSON, 2005), ainda que seja 
possível identificar interesses comuns, como no caso das políticas de infraestrutura de transporte regional (GERBER \& GIBSON, 2009).

Em segundo lugar, o dilema dos governos locais entre ceder autoridade ou não à organização regional (TAVARES \& FEIOCK, 2013; GERBER \& GIBSON, 2005 E 2009) se associa frequentemente à delegação seletiva de poderes ou à manutenção de regras consensuais ou supermajoritárias, assegurando individualmente aos governos locais o poder de veto. Há evidências de que nestes casos, burocracias regionais teriam menor autonomia e haveria maior proporção de recursos alocados em projetos de benefício local em detrimento daqueles de benefício regional (GERBER \& GIBSON, 2005; 2009).

Diferentemente dos estudos sobre parcerias intergovernamentais, estudos de governança regional estão focados nos problemas de ação coletiva entre governos locais. A ênfase nos efeitos das heterogeneidades dos pactuantes e no dilema de delegação de autoridade regional sugere a distinção entre cooperação para promover interesses comuns dos governos locais e cooperação para gerir interesses regionais. Tais aspectos não são tão relevantes quando se trata de governos locais identificarem uma agenda cooperativa em torno de interesses comuns, como nas parcerias intergovernamentais, mas o são quando se trata de ampliar o escopo cooperativo para ações redistributivas ou destinadas à absorção de externalidades negativas, também de grande importância do ponto de vista regional.

\section{REGIÕES METROPOLITANAS}

Parte dos estudos de governança regional cobrem organizações regionais que abrangem aglomerados urbanos densos, nos quais a proximidade física entre jurisdições locais e a integração entre atividades envolvendo mais de uma delas cria condições particularmente desafiadoras para a cooperação interlocal. Optamos aqui por segrega-los como um terceiro grupo por considerar que neste caso, como será argumentado nesta seção, a condição metropolitana cria um contexto interativo qualitativamente distinto para a solução dos problemas de cooperação.

Inicialmente cabe registrar que o conceito de regiões metropolitanas comporta definições distintas. Na visão da OCDE, este conceito se prende à definição de região funcional, compreendendo a abrangência espacial do mercado de trabalho, ou seja, comportando o território onde circulam compradores e vendedores da força de trabalho amarrados pelas respectivas relações contratuais. Para 
sua operacionalização, a infraestrutura de transportes configura um elemento chave, uma vez conectando trabalho e residência ou, mesmo, compradores e vendedores oriundos de diferentes localidades em transações comerciais cotidianas (OCDE, 2004). Entretanto o que difere a metropolização em uma região funcional é o processo de integração a partir de uma cidade-núcleo, configurando um território ampliado em que se compartilha um conjunto de funções de interesse comum (IPEA, 2010). Não se trata tão somente de um processo de concentração de atividades produtivas (ARRAIS, 2012), mas de uma polarização que reverbera do processo de integração territorial em um raio que abrange municípios periféricos. Os espaços de continuidade ou proximidade dos espaços urbanos de jurisdições locais fortalecem, assim, a interdependência entre decisões e processos desencadeados em cada localidade, de modo que questões de desenvolvimento urbano, infraestrutura ou políticas sociais raramente poderiam ser solucionadas por meio de medidas isoladas dos governos locais, ao contrário de outros tipos de regiões funcionais.

Deste modo, mais expostos a externalidades negativas, municípios de regiões metropolitanas vivem sob menores capacidades de solução unilateral de problemas locais que municípios de outras regiões funcionais. Essa condição afeta, por exemplo, o dilema delegatório descrito na seção anterior. Há igualmente o risco de que a delegação de grandes poderes a um órgão regional metropolitano o leve a perder o controle sobre grande parte das decisões que afetam seus problemas; porém a escolha por não delegar tais poderes, se por um lado conserva suas prerrogativas decisórias intactas, por outro não lhes assegura os efeitos presumidos das decisões locais já que estes também dependeriam das decisões tomadas pelos "vizinhos". Afastar a presença de uma organização coletiva capaz de tomar decisões vinculantes sobre temas regionais pode significar a manutenção de espaços úteis de autonomia em regiões funcionais não metropolitanas, mas afastá-la no caso das cidades metropolitanas não significa o mesmo.

Isso não significa, entretanto, que municípios metropolitanos sejam mais suscetíveis a resolver o dilema delegatório em favor das organizações regionais metropolitanas. Estudo recente da OCDE identificou quatro padrões de governança metropolitana: (1) Coordenação soft pela informação: compartilhamento de informação e consultorias, de fácil implementação e sem ferramentas de enforcement; (2) Autoridades intermunicipais: compartilhamento de custos e responsabilidades entre municípios para propósitos específicos ou finalidades múltiplas, abrangendo políticas como infraestrutura e transporte, por exemplo; (3) Autoridades supra municipais: camada de autoridade acima dos municípios, podendo incluir governos metropolitanos eleitos ou designados por níveis de governo 
mais abrangentes, como o nacional ou os provinciais; (4) Status especial de cidade Metropolitana: condição advinda de ultrapassar dimensão populacional legalmente definida, sob a qual uma região adquire o mesmo nível de poderes e competências que o próximo nível de governo (OCDE, 2014).

Savitch \& Adhikari (2016) propõem uma classificação mais parcimoniosa para estruturas de governança existentes nas regiões metropolitanas. De um lado estariam as instituições supralocais, capacitadas para atuar além dos interesses locais e deter autonomia para praticar políticas de forma independente; de outro, acordos intermunicipais, que atuariam nos limites previamente autorizados pelos governos locais e seriam estabelecidos voluntariamente pelos membros locais.

A despeito dessa variedade de formas de governança, parte considerável dos estudos aponta para suas limitações para atuar na solução de problemas regionais: seja porque seus formatos institucionais são fundados na adesão voluntária de governos locais ou porque adotam processos decisórios apoiados sobre o consenso ou super maiorias. Krukowska \& Lackowska (2017), nessa direção, chamam atenção para a relutância das autoridades locais polonesas na institucionalização das novas entidades políticas de governança metropolitana estimuladas pela União Europeia, sob o modelo do Investimento Territorial Integrado - ITI, e sua preferência por modelos organizacionais que evitem decisões vinculatórias e preservem a autonomia municipal, o que limitaria demasiadamente o foco das intervenções metropolitanas. Já Orfield \& Dawes (2016), analisando as 25 maiores áreas metropolitanas dos Estados Unidos, as caracterizam como pobremente governadas e incapazes de lidar com congestionamentos, segregação econômica e racial, bem como com disparidades na qualidade dos serviços. Atribuem o agravamento desses problemas à natureza fragmentada dos sistemas em que são governadas e que geram uma competição que encoraja jurisdições locais a perseguirem políticas sociais e econômicas com ganhos agregados pouco relevantes ou inexistentes, já que governos locais terminam simplesmente por atraírem ativos uns dos outros. Por fim, sua conclusão é precisa, ao destacar que tais organizações deixariam fora da agenda, exatamente, os temas que afetam a região como um todo, essencialmente aqueles de natureza social e redistributiva como as políticas habitacionais.

Ainda nessa direção, há estudos da OCDE apontando a fragmentação das jurisdições administrativas locais como o grande obstáculo à adequação das estruturas institucionais e financeiras de governança metropolitana, criando um ambiente decisório desfavorável para a realização de objetivos de médio e longo prazo, como a ordenação do crescimento urbano (OCDE, 2004). Porém, a despeito da grande variação dos poderes das organizações metropolitanas entre países membros da 
OCDE, menos de um quinto delas reúne poder suficiente para impor regulações no plano regional, sendo amplamente majoritários os arranjos de governança metropolitana de tipo soft (OCDE, 2014).

Savitch \& Adhikari (2016) analisaram as Public Authorities, entidades corporativas formadas por governos locais em áreas metropolitanas para propósitos múltiplos, identificando o que chamaram de regionalismo fragmentado, marcado por frustrações pela ausência de ações territorialmente integradas e adoção de iniciativas seletivas que não afetam desigualdades internas, déficits democráticos e fragmentação política. As Public Authorities apenas têm promovido políticas vinculatórias de forma seletiva: excluindo do seu escopo as políticas redistributivas como habitação, por exemplo, em favor de projetos de infraestrutura comum, em um quadro de fortes e crescentes disparidades econômicas internas.

A combinação entre regras decisórias consensuais e resultados políticos subótimos, encontrada nestes estudos, remete à "armadilha da decisão conjunta" descrita por Fritz Scharpf (1988) ao se referir aos impasses do federalismo alemão e à lentidão das reformas realizadas na transição para a União Europeia. A "armadilha" denota uma combinação entre frustração de expectativas de solução de problemas coletivos e resiliência de processos decisórios baseados em supermaiorias ou consenso, sob os quais unidades de governo beneficiadas pelo status quo bloqueiam opções redistributivas ou coletivamente eficientes.

A prevalência dos interesses das partes sobre o coletivo é denunciada por Orfield \& Dawes (2016) ao criticarem o uso de regras supermajoritárias ou consensuais nas organizações metropolitanas. Dado que políticas metropolitanas raramente decorrem de um processo livre de conflitos e, portanto, isento de eleger perdedores e ganhadores, não haveria como atender os interesses de todas as localidades, ao mesmo tempo, nas decisões acerca dos grandes problemas regionais. A governança regional efetiva e democrática, segundo os autores, requereria estruturas decisórias distintas das existentes, majoritariamente baseadas em corpos diretivos não eleitos e pouco capacitadas para executar o planejamento regional e coordenar a provisão de serviços como transporte, usos do solo, habitação e meio ambiente.

Estudo realizado pela OCDE analisando resultados das estruturas de governança metropolitana na Alemanha, Espanha, Estados Unidos, México e Reino Unido sugere que a falta de solução para problemas regionais produz efeitos econômicos. Segundo ele, há associação entre maior fragmentação territorial e menor desempenho em termos de produtividade. Ainda de acordo com dados da OCDE, apenas $10 \%$ das estruturas de governança metropolitana dos países membros tem corpos diretivos 
eleitos diretamente, o que ocorre principalmente sob a forma de autoridades supramunicipais e cidades metropolitanas (OCDE, 2014).

Para além de estudos de caso apontando experiências bem-sucedidas, muitos dos quais patrocinados pela própria $O C D E$, de um modo geral os estudos aqui agrupados têm se referido às associações metropolitanas, sob as mais diversas formas encontradas, a partir da associação entre resultados políticos aquém das necessidades regionais e a baixa independência institucional dessas organizações para agir sem o consenso dos governos locais associados. Ainda que haja espaço para iniciativas consensuais em torno dos interesses comuns dos associados, o elevado nível de heterogeneidades ou desigualdades entre eles, a interpendência entre decisões locais e maior susceptibilidade à produção de externalidades negativas as torna demasiadamente limitadas para solucionar os problemas metropolitanos.

\section{DISCUSSÃO}

Descritos os agrupamentos de estudos internacionais pertinentes a problemas de cooperação interlocal, retomamos as duas questões iniciais deste trabalho: como distingui-los quanto à natureza das organizações tomadas como objeto e, a partir daí, a que tipo de articulação entre interesses dos seus associados se referem. Por meio do quadro 1, a seguir, sintetizamos nossas respostas a essas questões.

Quadro 1 - Agrupamentos de estudos sobre problemas de cooperação interlocal na literatura internacional.

Quanto à primeira questão, os agrupamentos de estudos aqui segregados se referem a tipos distintos de associações envolvidas na cooperação interlocal. Estudos sobre parcerias voluntárias, embora abrangendo associações bastante distintas entre si, focam organizações classificadas por Feiock (2013) como "contratos" para cooperação, que podem se constituir em torno de uma ou mais issues de modo a buscar ganhos de economia de escala, atraindo maior atenção na literatura europeia como uma das alternativas à amalgamação e à privatização associada de serviços locais. Já estudos sobre governança regional, ainda que lidem com organizações com objetivos mais amplos - além de buscar obter ganhos em economia de escala, incluem também absorção de externalidades negativas, ações de benefício regional ou redistributivas - concentram-se naquelas que, embora voluntárias, envolvem algum grau de delegação de autoridade como ocorre nos Regional Councils norte americanos. Já estudos 
focando regiões metropolitanas se apoiam sobre organizações em que, embora variando bastante quanto aos seus poderes, forma de designação das direções (eleições ou nomeação) e desenho institucional, abrangem aglomerados urbanos em que governos locais guardam uma grande relação de proximidade entre si, o que gera maior interdependência entre suas ações e maior demanda por benefícios regionais em detrimento de geração compartilhada de benefícios locais. As organizações, neste último caso, podem incluir versões soft próximas dos acordos gerados sob as parcerias voluntárias, passando por estruturas de integração regional multifuncionais como aquelas enfocadas pela governança regional, até a constituição de autoridades metropolitanas eleitas.

Considerando este último ponto, nota-se que a distinção entre os três agrupamentos de estudos quanto à natureza das organizações abordadas, mais que uma correspondência estanque e exaustiva, se assemelha a uma relação de inclusão progressiva entre elas. Estudos de governança regional também podem incluir parcerias voluntárias, portanto focadas estritamente no interesse comum dos membros, mas o contrário não ocorre: estudos sobre parcerias voluntárias não incluirão associações cujo escopo cubra problemas redistributivos regionais, mitigação de externalidades negativas ou apresente dilemas delegatórios. De modo similar, estudos sobre regiões metropolitanas podem incluir experiências de parcerias voluntárias entre municípios constituintes, assim como podem lidar com o problema da ampliação de escopo cooperativo ou dilemas de delegação típicos dos estudos de governança metropolitana, mas se distinguirão destes por agregar como "camada adicional" a lida com problemas relativos à forte interdependência entre decisões locais e aos movimentos pendulares diários entre jurisdições, demandando soluções regionais integradas. Deste modo, os três agrupamentos de estudos se relacionam entre si como algo mais próximo de "bonecas russas" por meio de uma inclusão progressiva das parcerias voluntárias, passando pela governança regional até a gestão de regiões metropolitanas.

Parece interessante retomar, a esta altura, a tipologia proposta por Feiock (2013) para classificação dos arranjos de cooperação regional em quatro categorias. Uma primeira seria a integração informal em rede, baseada na confiança e reciprocidade entre gestores locais. A segunda, acordos contratuais pontuais para ações conjuntas voluntárias, não implicariam dilemas delegatórios e se restringiriam a interesses comuns. A terceira, delegação voluntária de autoridade para uma organização regional, de caráter multifuncional e detendo alguma autonomia para agir sem autorização prévia dos governos locais. Por fim, a quarta categoria incluiria a constituição de uma autoridade regional para atuar em determinada área de governo, como é o caso dos distritos especiais. A tomar por esta tipologia, 
estudos sobre parcerias voluntárias corresponderiam ao segundo tipo, enquanto os sobre governança regional se concentrariam no terceiro e os sobre regiões metropolitanas se distribuiriam entre o terceiro e, minoritariamente, quarto tipos.

Por outro lado, variando os tipos de organizações, variam também as agendas de pesquisa entre os agrupamentos de estudos. Parecerias intergovernamentais se orientam principalmente pela mensuração dos ganhos em termos de eficiência, em especial pela realização de economias de escala, considerando a necessidade de fixar mais precisamente as condições em que estas ocorrem e comparar com outras alternativas como a privatização associada e amalgamação, embora também incluam estudos interessados no esclarecimento das condições de adesão dos governos locais. Estudos de governança regional apresentam uma agenda de pesquisa ampla onde se busca fixar o peso de diferentes fatores que efetivamente afetem os custos de transação na barganha interlocal e que possam contribuir para explicar o nível de delegação de autoridade para organizações regionais, o quanto elas oferecem em termos de benefícios regionais vis a vis benefícios locais, dentre outros aspectos. Por fim, estudos sobre a gestão de regiões metropolitanas focam essencialmente no problema da constituição dos poderes metropolitanos, a partir do dilema delegatório, e das limitações de adotar as soluções coletivas demandadas por estes aglomerados urbanos, sob os mais diversos aspectos como a capacidade de oferecer ações redistributivas ou de amortecimento de externalidades negativas.

Quanto à segunda questão, foi possível perceber que os agrupamentos de estudos se distinguem quanto à maneira como organizações articulam os interesses dos governos locais. Estudos voltados para parcerias intermunicipais lidam com situações em que governos locais perseguem a realização de interesses que, embora particulares, são comuns ou compartilhados por todos. Cada um espera, agindo em conjunto, obter benefícios superiores àqueles que poderia obter unilateralmente e a agenda cooperativa exclui temas sobre os quais governos locais mantêm preferências distintas ou conflitantes, o que não significa que tais parcerias estejam livres dos riscos de comportamentos free rider e que demandem por regras e procedimentos de enforcement para contratos firmados. Já estudos sobre governança regional abordam associações em que governos locais, além dos interesses comuns, lidam com problemas ou temas regionais acerca dos quais não necessariamente mantêm interesses compartilhados. O grau de autonomia concedido às organizações regionais e a amplitude da agenda cooperativa, entretanto, varia entre as organizações tomadas por objeto destes estudos, dependendo principalmente de fatores como a heterogeneidade entre municípios, que possam aumentar substancialmente os custos de transação para incorporação de temas conflitantes ou externalidades 
negativas na pauta cooperativa. Por fim, estudos sobre regiões metropolitanas lidam igualmente com interesses não comuns entre suas jurisdições constituintes, porém sob um contexto de maior interdependência entre suas decisões locais. Diferente dos estudos sobre governança regional, os efeitos negativos advindos de soluções minimalistas quanto à autoridade regional investida no processo delegatório são menos localizados, dado que optar por preservar maior autonomia local não significa maior capacidade de realizar as preferências políticas locais, sendo os efeitos das próprias ações sujeitos às externalidades produzidas pelas ações dos governos vizinhos.

\section{CONCLUSÃO}

A literatura internacional envolvida nos problemas de cooperação entre governos locais se estrutura a partir de associações de natureza distinta, nas quais se colocam diferentes problemas de articulação entre os interesses dos associados. Se nas parcerias voluntárias foca-se na realização de interesses comuns, com baixos graus de delegação de autonomia para a associação e alta restrição à agenda cooperação, nas organizações para governança regional e de gestão de regiões metropolitanas, a incorporação de interesses não comuns e inclusão de temas para os quais governos locais atribuem diferente saliência ou conflitam entre si gera tensões a partir da pressão para autonomização da associação e ampliação do seu escopo cooperativo, o que depende de uma combinação de fatores institucionais e contextuais.

Confrontada com a literatura brasileira sobre cooperação intermunicipal, esta distinção sobre a forma de articulação entre interesses dos associados nos chama para uma reflexão sobre aproximações e distanciamentos. A literatura política brasileira apresenta em comum a concentração de trabalhos voltados para parcerias voluntárias, nela representadas pelos consórcios intermunicipais (monotemáticos ou multifinalitários), e para regiões metropolitanas. Já estudos mais alinhados aos problemas tipicamente tratados pelos estudos de governança regional, ou que considerem formas cooperativas cujo escopo contemple benefícios coletivos ou aspectos redistributivos em dimensão regional, são rarefeitos e limitados a algumas poucas áreas de políticas públicas, como ocorre na formação das redes de atenção regionalizadas em saúde (MACHADO, 2013; SANCHO ET AL., 2017). Além disso, ao contrário da literatura internacional de modo geral, são poucos frequentes os estudos de caráter analítico e que mobilizem categorias relativas aos fatores que afetam o sucesso da ação coletiva ou mesmo abordagens econométricas focadas na mensuração dos ganhos de eficiência. 
Assim, considerando as profundas desigualdades territoriais e assimetrias entre capacidades locais que marcam o caso brasileiro, e a tomar pelas contribuições das literaturas sobre governança regional e regiões metropolitanas para o entendimento dos dilemas relativos à ampliação do escopo cooperativo além dos interesses comuns e promoção do desenvolvimento regional integrado, há uma agenda de pesquisa promissora para o aprofundamento em torno dos problemas de cooperação em outras políticas com arranjos regionalizados como no caso do turismo, da proteção ambiental ou da gestão de bacias hidrográficas, dentre outras. A delimitação dessas possibilidades de introduzir temas conflitantes ou que envolvam ações redistributivas na agenda cooperativa interlocal, presentes na literatura internacional, sugere que a restringir à abordagem de parcerias voltadas para o estrito interesse comum, em uma sociedade profundamente desigual como a nossa, não parece ser uma escolha razoável.

\section{REFERÊNCIAS BIBLIOGRÁFICAS}

ABRUCIO, Fernando. L. A Coordenação Federativa no Brasil: a experiência do Período FHC e os desafios do Governo Lula. Revista de Sociologia e Política, n. 24, p. 31-67, 2005.

ADELAJA, Adesoji O., GIBSON, Melissa A., \& RACEVSKIS, Laila A. Transaction costs and inter-jurisdictional cooperation: an application to land use collaboration. Journal of Public Affairs, v. 10, n. 4, p. 265-279, 2010.

ALLERS, Maarten A.; DE GREEF, J. A. Intermunicipal cooperation, public spending and service levels. Local Government Studies, v. 44, n. 1, p. 127-150, 2018.

ALLERS, Maarten A. \& GEETSEMA, J. Bieuwe. The Effects of Local Government Amalgamation on Public Spending, Taxation, and Service Levels: evidence from 15 years of municipal consolidation. Journal of Regional Science, v. 56, n. 4, p. 659-682, 2016.

ALMEIDA, Maria Hermínia T. Recentralizando a Federação? Revista de Sociologia e Política. v. 24, p. 2940, 2005.

ALMEIDA, Maria Hermínia T. O Estado no Brasil Contemporâneo: um passeio pela história. In: MELO, Carlos R; SÁEZ, M. A. A Democracia Brasileira: balanço e perspectivas para o século 21. Belo Horizonte: Editora UFMG, 2007, p.17-37.

ANDREWS, Rhys \& ENTWISTLE, Tom. Does Cross-Sectoral Partnership Deliver? An Empirical Exploration of Public Service Effectiveness, Efficiency, and Equity. Journal of Public Administration, Research and Theory, v. 20, n. 3, p. 679-701, 2010. 
ARRETCHE, Marta T. Democracia, federalismo e centralização no Brasil. Rio de Janeiro: FGV-FIOCRUZ, 2012.

BEL, Germá \& WARNER, Mildred E. Inter-Municipal Cooperation and Costs: expectations and evidence. Public Administration, n. 93, p. 52-67, 2015.

BEL, Germá \& FAGEDA, Xavier. Between privatization and intermunicipal cooperation: small municipalities, scale economies and transaction costs. Urban Public Economics Review, n. 6, p. 13-31, 2006.

BLOM-HANSEN, Jens; HOULBERG, Kurt; SERRITZLEW, Soren; TREISMAN, Daniel. Jurisdiction Size and Local Government Policy Expenditure: assessing the effect of municipal amalgamation. American Political Science Review, v. 110, n. 4, p. 812-831, 2016.

COASE, Ronald. The Problem of Social Cost. Journal of Law and Economics, v. 3, n. 1, p. 1-44, 1960.

CHEN, Yu; YEH, Anthony G. O; ZHANG, Yingxuan. Political tournament and regional cooperation in China: a game theory approach. The Annals of Regional Science, v. 58, n. 3, p. 597-622, 2017.

DI PORTO, Edoardo; PARENTI, Angela; PATY, Sonia; ABIDI, Zineb. Local government cooperation at work: a control function approach. Journal of Economic Geography, n. 17, p. 435-463.

FEIOCK, Richard C. Institutional Collective Action and Local Governance. Paper 5, Wayne State University, 2005. Disponível em https://digitalcommons.wayne.edu/cgi/viewcontent.cgi?article=1004\&context=interlocal_coop, consultado em 01/10/2018.

FEIOCK, Richard C. Rational choice and regional governance. Journal of Urban Affairs, n29, 1: 47-63, 2007.

FEIOCK, R. The Institutional Collective Action Framework. The Policy Studies Journal, v. 41, n. 3, p. 397425, 2013.

FERNANDES, Antônio. S. A. Gestão Metropolitana no Brasil em perspectiva comparada: os casos das Regiões Metropolitanas de Salvador e Belo Horizonte. Cadernos Adenauer, v. XII. p. 219-234, 2011.

FRÈRE, Quentin, LEPRINCE, Matthieu; PATY, Sonia. The Impact of Intermunicipal Cooperation on Local Public Spending. Urban Studies, v. 51, n. 8, p. 1741-1760, 2013.

FURMANKIEWICZ, Marek. Leader+ territorial governance in Poland: successes and failures as a rational choice effect. Tijdschrift voor economische en sociale geografie, v. 103, n. 3, p. 261-275, 2012.

GARSON, Sol. Regiões metropolitanas - diversidade e dificuldade fiscal da cooperação. Cadernos Metrópole, v. 11, n. 22, p. 435-451, 2009.

GERBER, Elisabeth R. \& GIBSON, Clark C. Balancing Competing Interests in American Regional Governance. American Democracy Speaker Series. South Bend: Notre Dame University, 2005. 
GERBER, Elisabeth R. \& GIBSON, Clark C. Balancing Regionalism and Localism: how institutions and incentives shape American transportation policy. American Journal of Political Science, v. 53, n. 3, p. 633-648, 2009.

HAWKINS, Christopher V. Competition and Cooperation: Local Government Joint Ventures for Economic Development. Journal of Urban Affairs, v. 32, n. 2, p. 253-275, 2010.

HOLZINGER, K. The Problems of Collective Action: A New Approach. Bonn: Max Planck, 2003.

IPEA. Instituto de Pesquisa Econômica Aplicada. Infraestrutura Social e Urbana no Brasil: subsídios para uma agenda de pesquisa e formulação de políticas públicas. Livro 6, Vol. 2. Brasília, 2010.

KRUKOWSKA, Joanna; \& LACKOWSKA, Marta. Metropolitan Colours of Europeanization. Institutionalization of Integrated Territorial Investment Structures in the Context of Past Cooperation in Metropolitan Regions. Raumforschung und Raumordnung-Spatial Research and Planning, v. 75, n. 3, p. 275-289, 2017.

KWON, Sung-Wook. Regional governance institutions and interlocal cooperation for service delivery. Working Group on Interlocal Services Cooperation, 2007. Disponível em https://digitalcommons.wayne.edu/cgi/viewcontent.cgi?article=1029\&context=interlocal_coop, consultado em 01/10/2018.

LACERDA, Alan Daniel F. Ação Coletiva e Cooperação Intermunicipal em Duas Metrópoles. Caderno CRH, v. 24, n. 61, p. 153-166, 2011.

LAVALLE, Adrian Gurza; RODRIGUES, Maira; \& GUICHENEY, Hellen. (2019). Agência local e indução federal: a operação da política municipal de habitação em Recife e Curitiba. Revista de Sociologia e Política, v. 27, n. 71, 2019.

LINHARES, Paulo. T; CUNHA, A. S.; FERREIRA, A. P. L. Cooperação federativa: a formação de consórcios entre entes públicos no Brasil. In LINHARES, Paulo de Tarso; MENDES, Constantino C; LASSANCE, Antônio. Federalismo à brasileira: questões para discussão. Brasília: Ipea, 2012.

LIPPI, M. F. Governança e Governabilidade Regional: uma análise da Região Metropolitana da Baixada Santista. Cadernos Adenauer, v. XII, p. 203-218, 2011.

LOFLER, E. A gestão da responsabilização nas parcerias intergovernamentais. Revista do Serviço Público, v. 1, n. 1, p. 5-34, 2000.

MACHADO, José A. Ação Coletiva e Provisão de Bens Públicos por Meio de Formas Consorciadas entre Governos Locais: os consórcios intermunicipais de saúde no Brasil. Teoria \& Sociedade, n. 18.1, p. 144165, 2010. 
MACHADO, José A. Pacto de Gestão na Saúde: até onde esperar uma "regionalização solidária e cooperativa"? In HOCHMAN, Gilberto; FARIA, Carlos A. P. Federalismo e Políticas Públicas no Brasil. Rio de Janeiro: Editora FIOCRUZ, 2013.

MACHADO, José. A. \& ANDRADE, Marta. L. C. Cooperação intergovernamental, consórcios públicos e sistemas de distribuição de custos e benefícios. Revista de Administração Pública, v. 48, n. 3, p. 695-720, 2014.

MOURA, Rosa; LIBARDI, Diocles; BARION, Maria. I. Institucionalização de Regiões Metropolitanas: qual o sentido? Revista Paranaense de Desenvolvimento, n. 111, p. 129-143, 2006.

NIAOUNAKIS, Thomas \& BLANK, Jos. Inter-municipal cooperation, economies of scale and cost efficiency: an application of stochastic frontier analysis to Dutch municipal tax departments. Local Government Studies, v. 43, n. 4, p. 533-554, 2017.

OCDE. Territorial Reviews - Montreal, Canada. Paris: OCDE, 2004. Disponível em < https://www.oecdilibrary.org/urban-rural-and-regional-development/oecd-territorial-reviews_19900759>, Acesso em $10 / 10 / 2018$.

OCDE. Regional Outlook Regions and Cities: where policies and people meet. Paris: OCDE, 2014. Disponível em < https://read.oecd-ilibrary.org/urban-rural-and-regional-development/oecd-regionaloutlook-2014_9789264201415-en\#page1>, acesso em 10/10/2018.

OLSON JÚNIOR, M. The Logic of Collective Action: Public Goods and the Theory of Groups. New York, Schocken Books, 1968.

ORFIELD, Myron \& DAWES, Baris. Metropolitan Governance Reform. Local Government Reconsidered. Paper 8, 2016. Disponível em http://digitalcommons.chapman.edu/localgovernmentreconsidered/strengtheningdemocracy/papers/8, consultado em 05/10/2018.

PIRES, Roberto Rocha C. \& GOMIDE, Alexandre de Ávila. Governança e capacidades estatais: uma análise comparativa de programas federais. Revista de Sociologia e Política, v. 24, n. 58, p. 121-143, 2016.

ROCHA, Carlos Alberto V. \& FARIA, Carlos Aurélio P. Cooperação Intermunicipal, Reterritorialização da Gestão Pública e Provisão de Bens e Serviços Sociais no Brasil Contemporâneo: a experiência dos Consórcios de Saúde de Minas Gerais. Cadernos Metrópole, n. 11, p. 73-106, 2004.

SANCHO, Leyla G.; GEREMIA, Daniela S.; DAIN, Sulamis; GEREMIA, Fabiano; LEÃO, Cláudio J. S. O processo de regionalização da saúde sob a ótica da teoria dos custos de transação. Ciência \& Saúde Coletiva, v. 22, n. 4, p. 1121-1130, 2017.

SAVITCH, Hank V. \& ADHIKARI, Sarin. Fragmented Regionalism: why Metropolitan America continues to splinter. Urban Affairs Review, v. 53, n. 2, p. 381-402, 2016.

SCHARPF, Fritz W. The Joint-Decision Trap: lessons from German federalism and European integration. Public Administration, n. 66, p. 239-278, 1988. 
SKUZINSKI, Thomas S. Risk, Rationality, and Regional Governance. Doctoral Thesis. University of Michigan, Ann Arbor, 2015.

TAVARES, António F. \& FEIOCK, Richard C. Intermunicipal Cooperation and Regional Governance Europe: an institutional collective action framework. Paper presented at the European Consortium for Political Research General Conference, 2013. Disponível em https://pdfs.semanticscholar.org/d68a/18c54ecd758850440b692b19d81be7273de8.pdf, consultado em 06/10/2018.

TOMIO, Fabrício R. L. Federalismo, municípios e decisões legislativas: a criação de municípios no Rio Grande do Sul. Revista de Sociologia e Política, n. 24, p. 123-148, 2005.

Trabalho enviado em 28 de abril de 2021

Aceito em 20 de julho de 2021 